\title{
Greening in the circumpolar high-latitude may amplify warming in the growing season
}

\author{
Jee-Hoon Jeong • Jong-Seong Kug • Baek-Min Kim • \\ Seung-Ki Min · Hans W. Linderholm • Chang-Hoi Ho • \\ David Rayner $\cdot$ Deliang Chen $\cdot$ Sang-Yoon Jun
}

Received: 1 November 2010/ Accepted: 6 July 2011/Published online: 26 July 2011

(C) Springer-Verlag 2011

\begin{abstract}
We present a study that suggests greening in the circumpolar high-latitude regions amplifies surface warming in the growing season (May-September) under enhanced greenhouse conditions. The investigation used a series of climate simulations with the Community Atmospheric Model version 3-which incorporates a coupled, dynamic global vegetation model — with and without vegetation feedback, under both present and doubled $\mathrm{CO}_{2}$ concentrations. Results indicate that climate warming and associated changes promote circumpolar greening with northward expansion and enhanced greenness of both the Arctic tundra and boreal forest regions. This leads to additional surface warming in the high-latitudes in the growing season, primarily through more absorption of incoming solar radiation. The resulting surface and tropospheric warming in the high-latitude and Arctic regions weakens prevailing tropospheric westerlies over $45-70 \mathrm{~N}$,
\end{abstract}

J.-H. Jeong · H. W. Linderholm · D. Rayner · D. Chen Department of Earth Sciences, University of Gothenburg, Gothenburg, Sweden

J.-S. Kug (ه)

Korea Ocean Research and Development Institute, Ansan, Korea e-mail: jskug@kordi.re.kr

\section{B.-M. Kim}

Korea Polar Research Institute, Inchon, Korea

S.-K. Min

Climate Research Division, Environment Canada, Toronto, Canada

C.-H. Ho · S.-Y. Jun

School of Earth and Environmental Sciences,

Seoul National University, Seoul, Korea leading to the formation of anticyclonic pressure anomalies in the Arctic regions. These pressure anomalies resemble the anomalous circulation pattern during the negative phase of winter Arctic Oscillation. It is suggested that these circulation anomalies reinforce the high-latitude and Arctic warming in the growing season.

Keywords Vegetation - Arctic warming . Arctic greening - Climate model · Future climate . Atmospheric circulation - Surface energy budget

\section{Introduction}

The high-latitude and Arctic regions have experienced substantial climate warming in recent decades. The degree and rate of warming in these regions has been much greater and faster than for the global average temperature due to various climate feedbacks (e.g. Rothrock et al. 1999; Serreze et al. 2000; ACIA 2005; Chapin et al. 2005; Screen and Simmonds 2010). Great attention has been paid to the changes in the vegetation-ecosystems in the high-latitude and Arctic regions during this climate warming and to their potential to generate feedbacks and cause further climate change (e.g. Chapin et al. 2005; Foley 2005).

Associated with recent increase in temperature and the extension of growing season, significant enhancement of vegetation greenness in the Arctic tundra and grassland areas has been observed (Tucker et al. 2001; Zhou et al. 2001; Bunn et al. 2007), and also the expansion of shrubs in Northern Alaska and pan Arctic regions (Tape et al. 2006). The physiological effect of rising $\mathrm{CO}_{2}$ on vegetation (i.e., the $\mathrm{CO}_{2}$ fertilization effect) is suggested to have also contributed to these changes by increased 
photosynthesis of plants, particularly among C3 plants (Mooney et al. 1999). Such vegetation changes, in turn, affect the local climate system by altering the surface energy budget and hydrological cycle. For instance, if snow-covered or barren surfaces are replaced by vegetated surface, increased absorption of solar energy due to reduced surface albedo induces additional surface warming (Bonan et al. 1992; Foley et al. 1994; Chapin et al. 2005). On the other hand, an increase in vegetation activity has a surface-cooling effect if the enhanced vegetation activity induces a large increase in evapotranspiration from vegetated land surfaces (Jeong et al. 2009). Another possibility suggested is that an increase in vegetation activity (i.e., enhanced plant growth) may slow down the increasing concentration of $\mathrm{CO}_{2}$ and alleviate warming by carbon sequestration, the uptake of the atmospheric $\mathrm{CO}_{2}$ (Watson 2000). Hence it is widely recognized that the vegetation-climate feedback has a great potential to amplify or dampen either natural or anthropogenic climate change.

The significance of the vegetation-feedback effect for climate models' responses to anthropogenic climate forcings-and even to the paleo-climate perturbations-has been previously recognized (Bonan et al. 1992; Foley et al. 1994). Although the vegetation feedback operates differently depending on regional climate characteristics and vegetation types (Levis et al. 1999), climate model simulations generally suggest that the vegetation changes have a positive feedback effect on climate warming, particularly in the high-latitudes and Arctic-more vegetation growth feeds warming, which is mainly caused by reduced surface albedo (Bonan et al. 1992; Foley et al. 1994; Levis et al. 1999; Zhang and Walsh 2006; Notaro et al. 2007; Notaro and Liu 2008; O'ishi and Abe-Ouchi 2009; Swann et al. 2010).

The objective of the present study is to further investigate the role of vegetation feedback effects on the climate change response to greenhouse warming. By utilizing a fully coupled climate-vegetation model, a series of idealized simulations with present and doubled $\mathrm{CO}_{2}$ concentration are performed, both with and without vegetation feedback. The contribution of vegetation feedbacks to the changes is quantitatively estimated from several sensitivity experiments. The vegetation feedback effect to surface air temperature (SAT) and the associated surface energy budget are analyzed, and the associated large scale circulation change and its role in driving climate change in the high-latitude and Arctic are discussed.

The modeling system used and experiments performed are described in Sect. 2, the estimated vegetation feedback effect and circulation change are presented in Sect. 3, followed by discussion and summary in Sect. 4 .

\section{Model experiments}

\subsection{Model description}

To investigate the vegetation feedback effect under climate warming, a series of global climate model experiments are conducted using the Community Atmospheric Model version 3 (CAM3; Collins et al. 2004) an atmospheric general circulation model developed by the National Center for Atmospheric Research (NCAR). We use a version with a horizontal resolution of T42 (approximately $2.8^{\circ} \times 2.8^{\circ}$ ) and 26 hybrid-sigma vertical levels.

The land surface model incorporated with CAM3 is the Community Land Model version 3 (CLM3; Oleson et al. 2004), which adopts a dynamic global vegetation model (DGVM), a modified version of the Lund-Potsdam-Jena vegetation model (Sitch et al. 2003; Levis et al. 2004; and many references therein). The DGVM simulates the evolution of vegetation cover and structure under given climatic conditions. The DGVM represents global vegetation with 10 plant functional types (PFTs; see Table 2), and calculates every PFTs' leaf area index (LAI), canopy height, and fractional cover relative to the portion of the grid cell allocated to natural vegetation, which represents only 'non-agricultural' vegetation. Synchronous climatevegetation coupling enables CAM3-DGVM to consider the biogeophysical and biogeochemical interactions between climate and vegetation. The plant-atmosphere exchange of $\mathrm{CO}_{2}$ is parameterized by the DGVM, but the atmospheric concentration of $\mathrm{CO}_{2}$ is set to be fixed in the current CAM3-DGVM because the terrestrial carbon cycles are not fully resolved. If not coupled to the DGVM, CAM3 runs with prescribed fractional cover and seasonal cycle of LAI of PFTs estimated from satellite observation.

\subsection{Experimental design}

A potential distribution of present-day vegetation is obtained by a spin-up simulation of the CAM3-DGVM for 500 years under 'present' climate forcings: i.e., $355 \mathrm{ppmv}$ $\mathrm{CO}_{2}$ concentration and observed climatological seasonal cycles (1961-1990) of sea surface temperatures (SST) and sea ice concentration derived from UK Met office Hadley center (Rayner et al. 2003). Evolving from an initial nonvegetated state, the simulated global vegetation fields reaches a quasi-equilibrium state in terms of the factional cover and LAI of global vegetation from about model year 350. The 'present' vegetation field, a possible state of global vegetation which could be reached under the 'present' climate condition without the interference of human activity, is taken from an average of last 50 years of the 'spin-up' simulation'. The simulated 'present' vegetation field captures fairly-well the major vegetated area with 
a reasonable seasonal cycle of plants' growth, despite some deficiencies (Levis et al. 2004).

Three ensemble experiments are performed to estimate the ' $\mathrm{CO}_{2}$ radiative effect' and 'vegetation feedback effect' from climate change under doubled $\mathrm{CO}_{2}$ concentration. A brief summary of the experiments are given in Table 1 . The first experiment, referred to as $\mathrm{P}$, is a ' $\mathrm{P}$ 'resent climate simulation. The $\mathrm{CO}_{2}$ concentration is fixed to $355 \mathrm{ppmv}$ (observed concentration in year 1992), and concentrations for other GHGs are taken from observed values for the same year; for instance, $\mathrm{CH}_{4}$ and $\mathrm{N}_{2} \mathrm{O}$ concentrations are set to 1.7090 and 0.3080 ppmv, respectively. By turning off the DGVM, the 'present' vegetation field: the fractional coverage and seasonal cycles of LAI for each of PFTs from the spin-up simulation is prescribed for this $\mathrm{P}$ experiment. The second experiment, referred to $\mathrm{F}$, is an idealized 'F'uture climate simulation. The $\mathrm{CO}_{2}$ concentration is doubled to 710 ppmv, but the 'present' vegetation field is again prescribed. Consequently, the difference between the $\mathrm{P}$ and $\mathrm{F}$ simulation is attributed to the radiative forcing due to the doubled $\mathrm{CO}_{2}$ concentration- ' $\mathrm{CO}_{2}$ radiative effect'. This term implicitly includes the contributions from changed sea ice and SST that arise under enhanced greenhouse conditions (see below). The third experiment, referred to FV, is another ' $\mathrm{F}$ 'uture climate simulation with the doubled $\mathrm{CO}_{2}$ concentration, but includes the 'V'egetation feedback effect by turning on the DGVM. Accordingly, the vegetation is allowed to respond to the overlying climate conditions, and so provide a feedback effect to climate. Hence, the difference between the FV and F is considered as the 'vegetation feedback effect' associated with the climate warming that results from doubling $\mathrm{CO}_{2}$ concentration.

In order to consider the ocean's impact on climate change, the climatological distribution of sea ice and SSTs derived from present and doubled $\mathrm{CO}_{2}$ simulations of NCAR Community Climate System Model version 3 (CCSM3; Collins et al. 2006) are prescribed as boundary conditions for the present $(\mathrm{P})$ and future $(\mathrm{F}$ and $\mathrm{FV}$ ) experiments respectively. The main features of the SST and sea ice differences between the present and future simulations of CCSM3 are overall warming in the SST and reduced sea ice concentrations in the Arctic region and Antarctic (figure not shown). With respect to the present values, the sea ice concentration over the Arctic sea (north of $65 \mathrm{~N}$ ) shows a $33.70 \%$ decrease, and the global mean

Table 1 Summary of experiments performed

\begin{tabular}{llll}
\hline & Vegetation & $\mathrm{CO}_{2}$ & SST/SIC \\
\hline $\mathrm{P}$ & Present prescribed & Present & Present \\
$\mathrm{F}$ & Present prescribed & Future & Future \\
$\mathrm{FV}$ & DGVM & Future & Future \\
\hline
\end{tabular}

SST increases by $1.62^{\circ} \mathrm{C}$ with relatively larger increase in the high-latitudes $\left(1.89^{\circ} \mathrm{C}\right.$ increase for $\left.60 \mathrm{~N}-90 \mathrm{~N}\right)$ in the May to September average.

All three experiments (P, F, and FV) are integrated for 100 years, with 5 ensemble members initiated by taking slightly different atmospheric initial conditions. Considering the adjustment time for the model, only the results for last 50 years of the experiments are utilized for analysis. Here we mainly focus on the temperature and atmospheric circulation changes in the growing season (May-September). This is the primary growing season for most vegetation in the Northern Hemisphere, and hence when the vegetation feedback effect is expected to be most pronounced. Ensemble averages from three experiments are compared, where the $\mathrm{CO}_{2}$ radiative and vegetation effect are defined as:

1. $\mathrm{CO}_{2}$ radiative effect ( $\mathrm{F}$ minus $\mathrm{P}$ )

2. Vegetation feedback effect (FV minus F)

3. All effect (FV minus P)

The statistical significance of each effect (i.e., a difference between two experiments) is calculated by a twosided Student's $t$ test based on the mean and standard deviation estimated from the 50-year simulation results.

\section{Results}

\subsection{Vegetation change under doubled $\mathrm{CO}_{2}$} concentration

CAM3 simulates surface temperature increases across the entire Northern Hemisphere $(\mathrm{NH})$ in response to the elevated $\mathrm{CO}_{2}$ concentration (Fig. 1). Most regions show SAT increases in the range of $1.5-2.5^{\circ} \mathrm{C}\left(2.1^{\circ} \mathrm{C}\right.$ for $\mathrm{NH}$ average over land) where the degree of warming tends to be relatively larger over dry, high-latitude continental regions. The magnitude of warming is comparable to that shown by the IPCC AR4 models for the second half of twenty-first century under the A1B scenario; an increase of about $2-3^{\circ} \mathrm{C}$ over land surface during summer (c.f. Fig. 13 in Chapman and Walsh 2007). Due to the differences between the prescribed SST and sea ice climatologies in the present (P) and future (F and FV) experiments, the reduced Arctic sea ice concentration and warmer SSTs in the high-latitudes in the future experiments may contribute to the relatively large warming in the high-latitude coastal regions. Precipitation also increases for most parts of the NH, particularly in high-latitude regions (Fig. 1b). Over some midlatitudes, e.g. the southern Europe and western North America, drier conditions are found. This feature results from atmospheric circulation changes associated with elevated $\mathrm{CO}_{2}$ concentration (Solomon et al. 2007). In general, 
Fig. 1 a The growing season (MJJAS) SAT and

b precipitation change by the all effect (FV-P). Areas with a difference significant at the $99 \%$ confidence level are stippled (a) SAT $\left[{ }^{\circ} \mathrm{C}\right]$ change by all effect

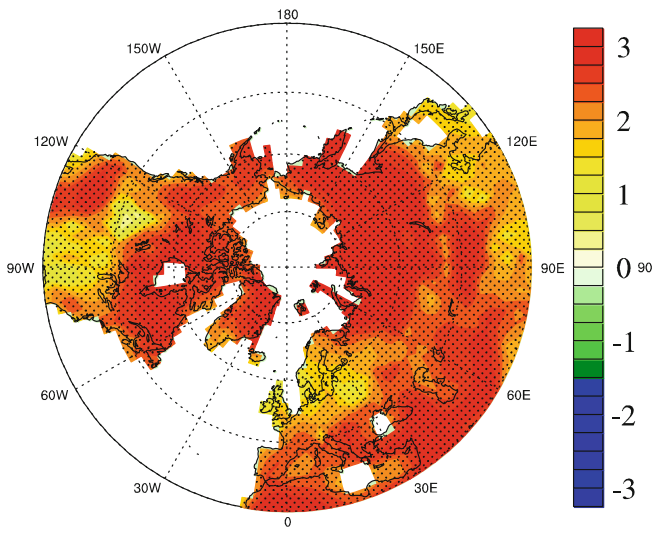

(b) Precipitation [mm/day] change by all effect

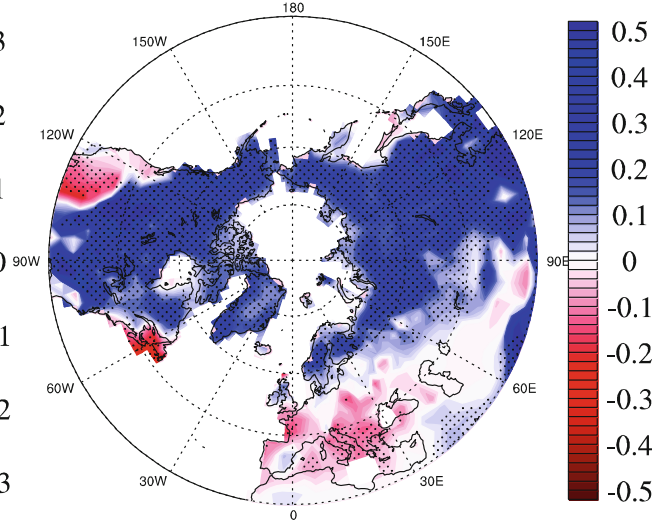

(a) Grasses [\%]

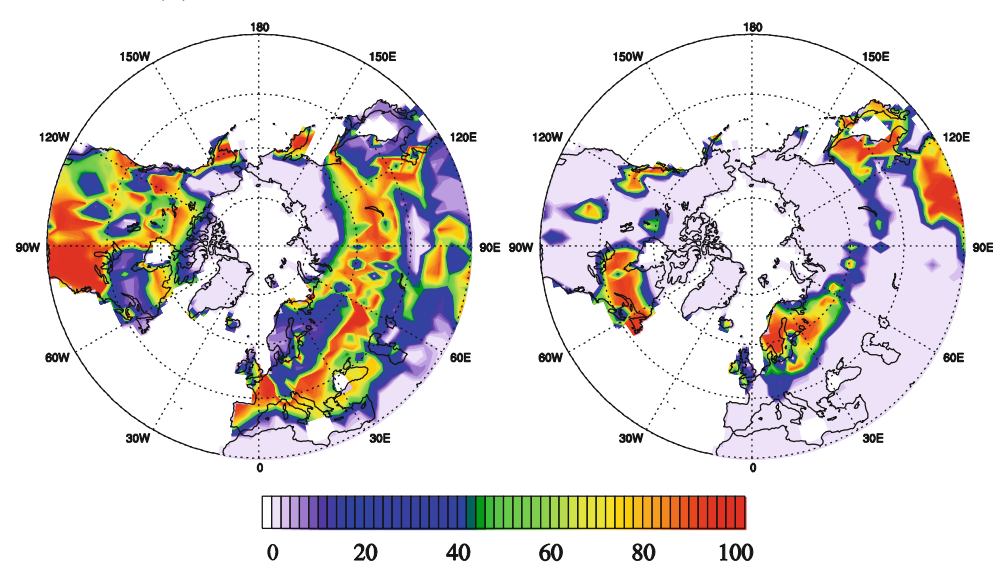

(d) Change in grasses [\%]

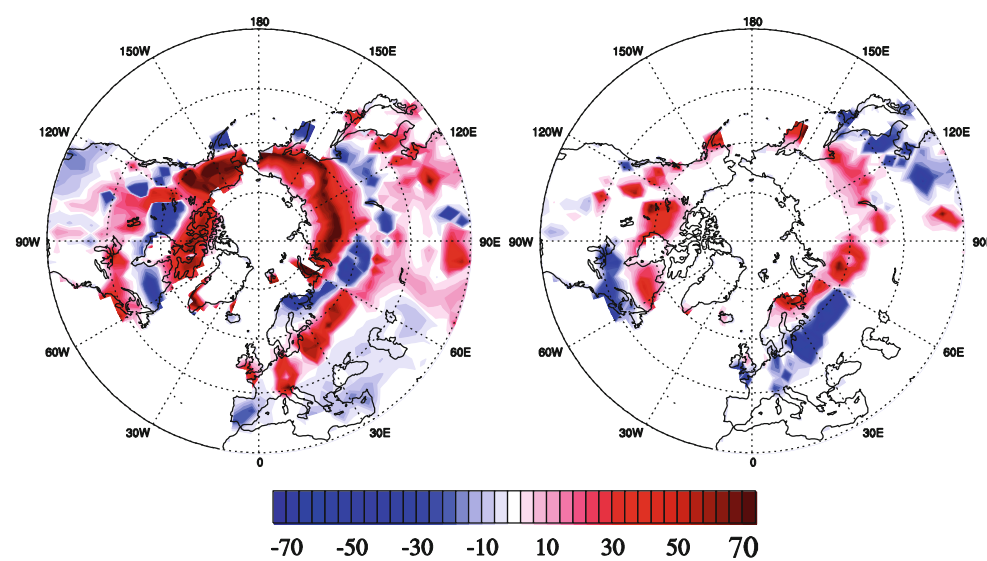

(c) Leaf area index

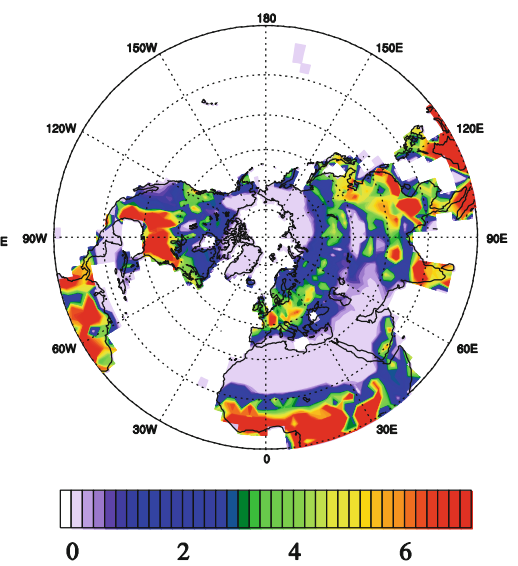

(f) Change in LAI

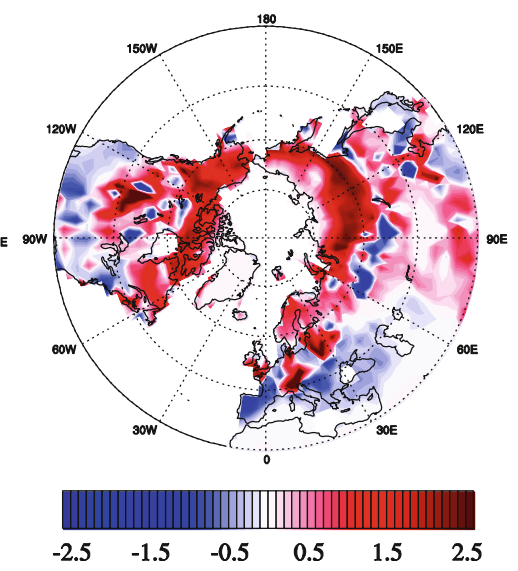

Fig. 2 Mean fractional cover of $\mathbf{a}$ grass and $\mathbf{b}$ tree species, and $\mathbf{c}$ mean leaf area index in the warm season under present level of $\mathrm{CO}_{2}$ concentration $(\mathrm{P})$. $\mathbf{d}-\mathbf{f}$ their change due to doubled $\mathrm{CO}_{2}$ (i.e. FV-P)

strong increases in temperature and precipitation in the Arctic and high-latitudes are most distinct, being consistent with results from previous observational and modeling studies (Chapman and Walsh 2007; Solomon et al. 2007; Min et al. 2008).
These changes in climate conditions affect the plant's establishments and growth, in addition to a direct physiological effect on plant's photosynthesis from the $\mathrm{CO}_{2}$ fertilization effect. Therefore, global vegetation exhibits considerable changes in its fractional coverage and LAI 
under a doubled $\mathrm{CO}_{2}$ climate. Figure 2 and Table 2 represent the overall vegetation change in the $\mathrm{NH}$ corresponding to a doubled $\mathrm{CO}_{2}$ climate. The most notable changes are found over the high-latitudes, north of $60 \mathrm{~N}$. The northward expansion and greening of plants are conspicuous over the northern rim of the high-latitudinal continents where low temperature and low radiation input are major environmental controls over plant's growth (Chapin 1983, 1987). The fractional covers of all PFTs increase, particularly for the Arctic grass group which more-than doubled (15.68-35.24\%) its fractional coverage. Along with the increase in the fractional coverage of vegetation, the vegetation greenness greatly increases over the high-latitudes; LAI increase from 0.70 for the P simulation to 1.49 for the FV simulation. On the other hand, the vegetation changes in the mid-latitudes $(30-60 \mathrm{~N})$ are relatively modest. The fractional coverages of $\mathrm{C} 3$ nonarctic grass and boreal broadleaf deciduous PFTs increase (29.62-34.60 and $4.94-5.52 \%$ respectively) but those of other plant species decrease slightly. The LAI slightly increases on average (2.42-2.61) but varies with location. A decrease in the LAI is detectable in western USA and southwestern Europe, where the growing season precipitation decreases slightly (Fig. 1b).

\subsection{Vegetation feedback effect on SAT}

The most pronounced feature of vegetation feedback effect on SAT is warming over high-latitude land areas associated with circumpolar greening (Fig. 3a). Large increases in SAT are found in the northernmost region of the Eurasian and North American continents. The average SAT anomaly resulting from the vegetation feedback effect for the land areas in north of $60 \mathrm{~N}$ is $0.3^{\circ} \mathrm{C}$. This warming effect is most pronounced in June and July; the area-averaged SAT change in the north of $60 \mathrm{~N}$ is 0.59 and $0.47^{\circ}$ respectively, and become insignificant in August and September $(0.20$ and $-0.02^{\circ} \mathrm{C}$ in the north of $60 \mathrm{~N}$ ) when plant activity in the high-latitude start to cease. In contrast, cooling dominates the mid-latitude land areas over North America, Western Europe, and East Asia. The zonal mean SAT change clearly shows the meridional structure of the vegetation feedback effect (Fig. 3b): enhanced warming of up to $0.4^{\circ} \mathrm{C}$ in the high-latitude north of $50 \mathrm{~N}$, and slight cooling

Table 2 Fractional [\%] cover of each PFT simulated by CAM3-DGVM under present $(\mathrm{P})$ and doubled concentration of $\mathrm{CO}_{2}(\mathrm{FV})$ and its change (FV-P)

\begin{tabular}{|c|c|c|c|c|c|c|}
\hline \multirow[t]{2}{*}{ Tree species } & \multicolumn{3}{|c|}{ High-latitudes $(60-90 N)$} & \multicolumn{3}{|c|}{ Mid-latitudes (30-60N) } \\
\hline & $\mathrm{P}$ & $\mathrm{FV}$ & FV-P & $\mathrm{P}$ & $\mathrm{FV}$ & FV-P \\
\hline Temperate needleleaf evergreen & 0.41 & 0.45 & +0.03 & 1.20 & 0.89 & -0.31 \\
\hline Boreal needleleaf evergreen & 2.98 & 3.62 & +0.64 & 6.69 & 6.40 & -0.29 \\
\hline Temperate broadleaf evergreen & 0.00 & 0.01 & +0.01 & 0.94 & 0.80 & -0.13 \\
\hline Temperate broadleaf deciduous & 2.32 & 3.09 & +0.77 & 6.49 & 6.19 & -0.29 \\
\hline Boreal broadleaf deciduous & 2.13 & 4.43 & +2.30 & 4.94 & 5.52 & +0.58 \\
\hline c3 arctic grass & 15.68 & 35.24 & +19.56 & 16.29 & 15.05 & -1.24 \\
\hline c3 non-arctic grass & 2.66 & 5.35 & +2.69 & 29.62 & 34.60 & 4.97 \\
\hline
\end{tabular}

Tropical broadleaf evergreen and temperate broadleaf evergreen, which are not found (zero fractional cover) over the domain for both $\mathrm{P}$ and FV, are not listed

Fig. 3 Vegetation feedback effect (FV-F) on a growing season SAT changes. Areas with a significant difference at the $99 \%$ confidence level are stippled. b zonal mean growing season SAT changes by all (FV$\mathrm{P}$; black solid line), $\mathrm{CO}_{2}$ radiative ( $\mathrm{F}-\mathrm{P}$; red dashed line), and vegetation feedback (FV-F; blue dotted line) effect in the growing season. The SAT is averaged over land (a) SAT $\left[{ }^{\circ} \mathrm{C}\right]$ change by vegetation feedback effect

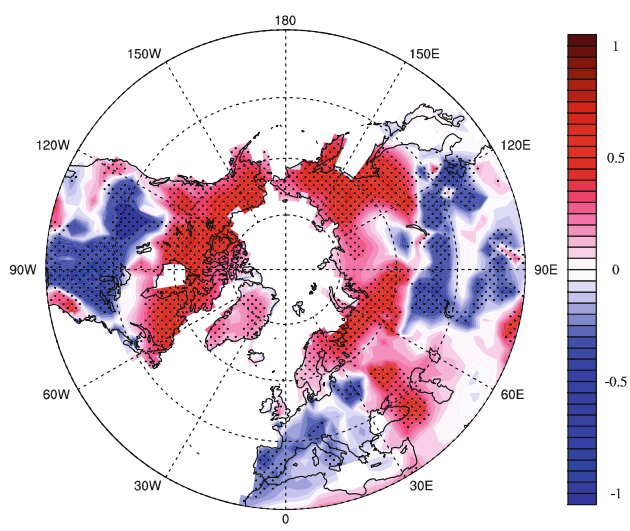

(b) Zonal mean SAT change $\left[{ }^{\circ} \mathrm{C}\right]$

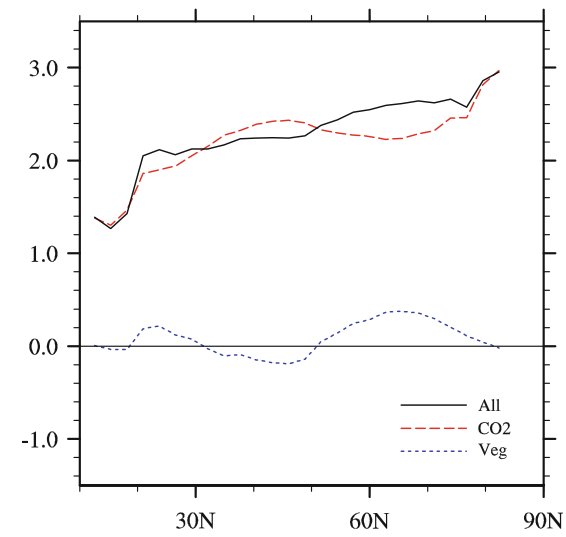


Fig. 4 Vegetation feedback effect (FV-F) on a zonal mean changes in absorbed SW (positive downward), emitted LW (positive upward), and net radiation (positive downward) at surface, and b zonal mean surface sensible and latent heat change (positive upward) over land in the growing season (a) Sfc radiation change by veg. feedback (FV-F)

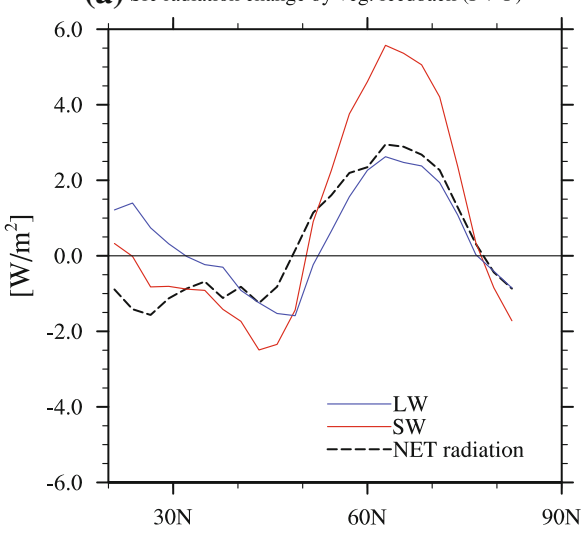

(b) Sfc E flux change by veg. feedback (FV-F)

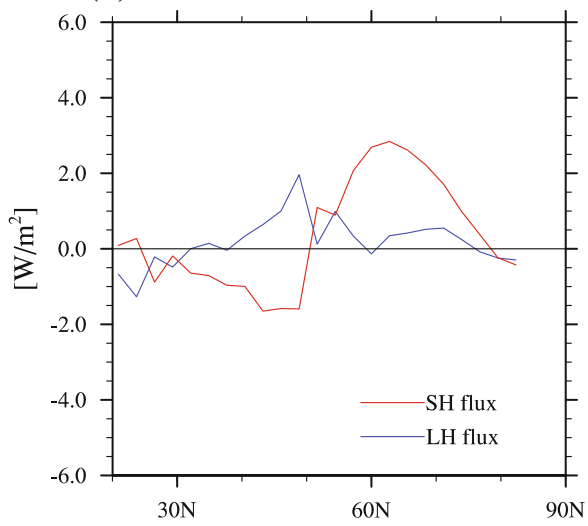

in the mid-latitudes. The well-defined meridional structure and contrast in SAT changes between the high- and midlatitudes provides the potential to induce atmospheric circulation change. This will be discussed further in the next section.

Two different physical feedback effects associated with the circumpolar greening can be considered as primary contributions to the SAT change; a decrease in surface albedo causes additional surface warming while an increases in latent heat (LH) fluxes associated with an increase in transpiration causes surface cooling. The change in surface radiation, and surface sensible heat ( $\mathrm{SH}$ ) and LH flux by vegetation change (Fig. 4) manifest the different contribution of the two feedback effects on the SAT change. In the high-latitude land regions (50-70N), an increase in absorbed shortwave radiation at surface ( $\mathrm{SW} \downarrow$ ) is notable. This is consistent with the vegetation increase in high-latitude regions, where increased vegetation cover and leaf abundance (i.e. higher LAI) reduces the surface albedo. Decreasing cloud cover over the high-latitude regions where the SAT warming is prominent additionally contributes to the increase in $\mathrm{SW} \downarrow$, but the change is considered to be modest (figure not shown). The emitted longwave radiation $(\mathrm{LW} \uparrow)$ increases with increased surface temperature, but the magnitude is about the half of the $\mathrm{SW} \downarrow$ increase (Fig. 4a). Consequently, there is a surplus in net incoming radiation at the surface, which is mostly balanced with an increase in sensible heat $(\mathrm{SH})$ release from surface (Fig. 4b). On the other hand, latent heat (LH) only increases slightly associated with a modest increase in precipitation from the vegetation feedback effect (figure not shown), causing a modest (evaporative) cooling effect at surface. Therefore, these feedbacks cause a net warming effect on near-surface air temperature.

In the mid-latitudes $(30-50 \mathrm{~N})$, both the $\mathrm{SW} \downarrow$ and $\mathrm{LW} \uparrow$ decrease from the vegetation feedback effect. As the decrease in $\mathrm{SW} \downarrow$ is larger than the decrease in $\mathrm{LW} \uparrow$, there is a net radiative cooling at the surface, which is mostly balanced with a decrease in SH flux. The vegetation changes in the mid-latitudes are horizontally uneven when compared to the changes in the circumpolar high-latitudes. This implies that vegetation feedbacks may cause other effects that induce cooling in the mid-latitudes. The largescale atmospheric circulation change by vegetation feedback, discussed in next section, contributes a cooling effect in the mid-latitudes, which partially offsets surface warming from increased $\mathrm{CO}_{2}$.

\subsection{Circulation changes from the vegetation feedback effect}

The circulation changes from the vegetation feedback effect are investigated by examining changes in atmospheric sea level pressure (SLP) and geopotential height (Z) (Fig. 5). There is an anomalous positive pressure center in Arctic region north of $50 \mathrm{~N}$, while negative pressure anomalies are found in the mid-latitudes over the north Pacific, East Asia, and northeastern America. Interestingly, this arctic high pressure/mid-latitude low pressure pattern in the growing season resembles the anomalous SLP pattern found during the negative phase of the AO, a primary internal dynamical mode of largescale atmospheric circulation variability (Thompson and Wallace 1998). Despite less pronounced mid-latitude centers in the North Atlantic and North Pacific compared to those in the winter AO pattern, the hemispheric pattern of the anomalous SLP and Z at 500 and $200 \mathrm{hPa}$ exhibit a well-defined negative AO-like structure. The structure extends from surface (Fig. 5a) through the mid- to uppertroposphere (Fig. 5b-c), and becomes more zonally-symmetric in the upper troposphere.

This negative AO-like circulation change is sustained by the circumpolar warming arising from the vegetation feedback effect. The vertical structures of the tropospheric wind and temperature changes from the vegetation feedback effect reveal a systematic dynamical relationship 
(a) SLP $\lfloor\mathrm{hPa}\rfloor$

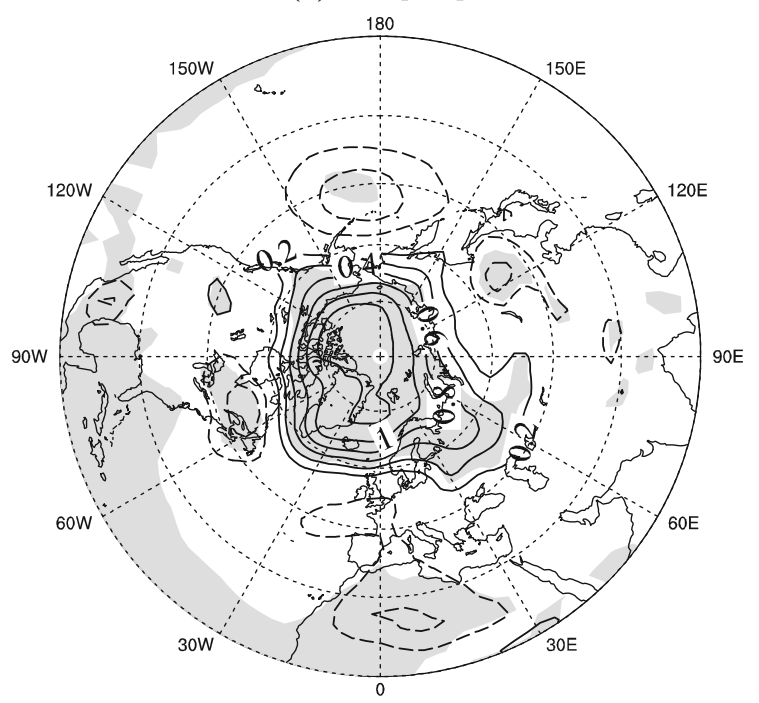

(b) $\mathrm{Z} 500[\mathrm{~m}]$

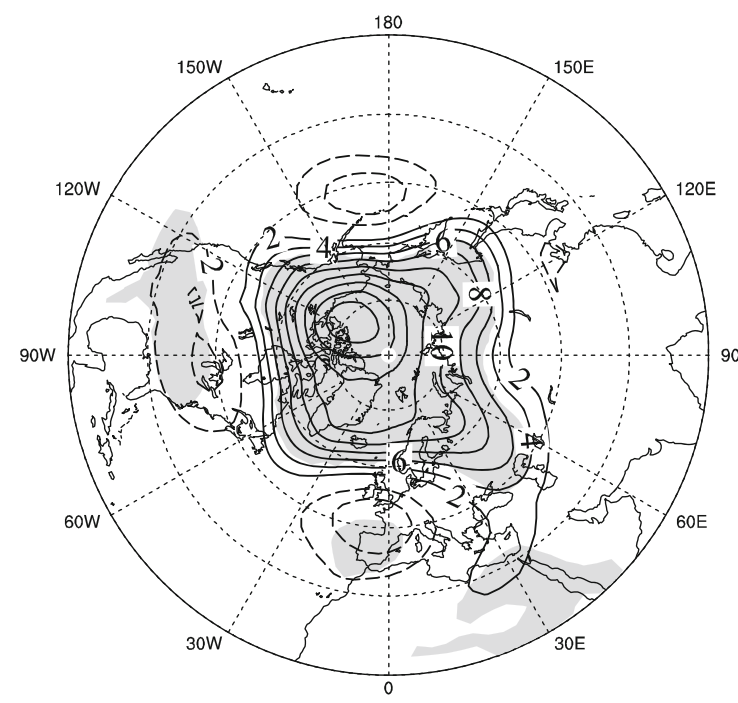

(c) $\mathrm{Z} 200[\mathrm{~m}]$

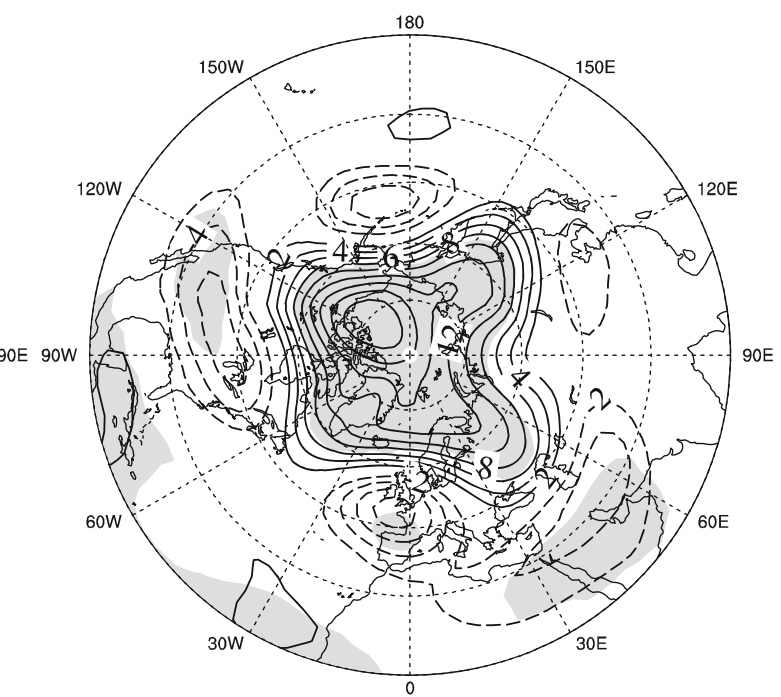

Fig. 5 Changes in a SLP, b Z at 500, and c $200 \mathrm{hPa}$ in the growing season by the vegetation feedback effect (FV-F). Solid and dashed lines indicate positive and negative values respectively, and gray shading indicates area with a significant difference at the $99 \%$ confidence level

between the circumpolar warming and circulation change (Fig. 6a). Tropospheric warming from the vegetation feedback is distinct over $50-70 \mathrm{~N}$ from the surface to lower to mid troposphere, extending to the Arctic region aloft. Surface warming in the Arctic region in winter tends to be mostly confined to near the surface due to very stablystratified atmospheric conditions (Tjernström and Graversen 2009). However, the atmosphere is less stable in the growing season, so moderate vertical mixing enables the lower tropospheric warming to be transported to the mid and upper troposphere. Additionally, an increase in surface roughness by the enhanced vegetation can induce more turbulence and vertical mixing by lowering aerodynamic resistance (Bonan 2008). Along the southern flank of the circumpolar warming, negative westerly wind anomalies throughout the troposphere are found around 50-70N, with a maximum at $60 \mathrm{~N}$ at $300-250 \mathrm{hPa}$. The latitudes of maximum decrease in zonal wind almost coincide with the latitudes of maximum increase in SAT. To a large extent, the anomalous wind and tropospheric temperature changes from the vegetation feedback satisfy a thermal wind balance relationship. The easterly wind anomalies, extending to the upper troposphere with a maximum value at $300 \mathrm{hPa}$, coincide with the decreased meridional temperature gradient caused by the circumpolar warming. The maximum altitude of the easterly wind anomalies is dynamically linked with the existence of the significant cooling over the polar cap region above $300 \mathrm{hPa}$. Kug et al. $(2010 \mathrm{a}, \mathrm{b})$ pointed out that such anomalous anticyclonic flow (i.e. a weakened polar vortex) induces a divergence of 
(a) Vegetation feedback effect

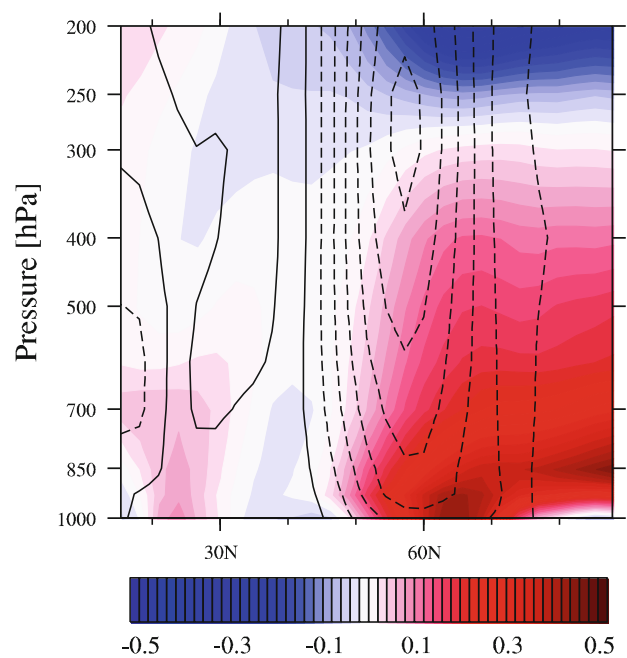

(b) $\mathrm{CO}_{2}$ radiative effect

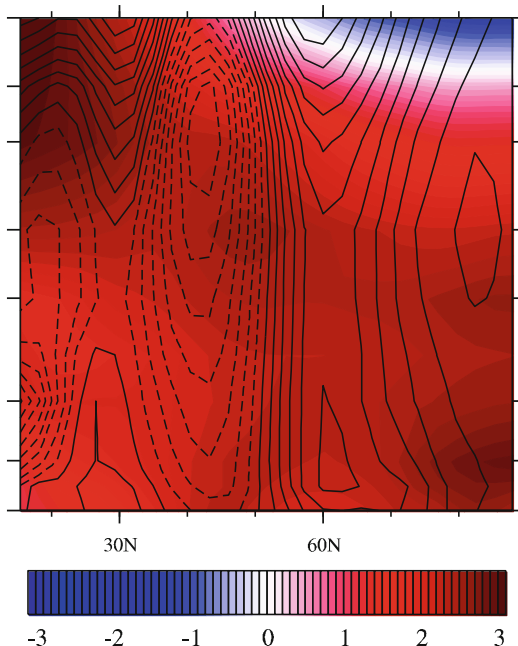

(c) All effect

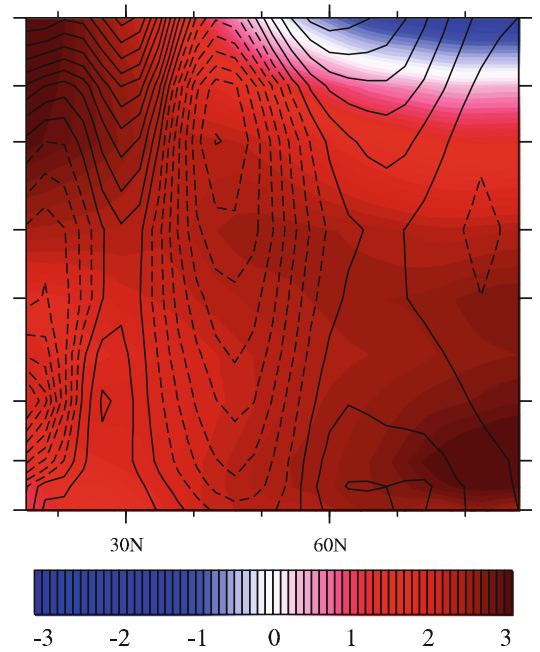

Fig. 6 Zonal mean temperature (shading, unit: $\mathrm{K}$ ) and zonal wind (contours, unit: $\mathrm{m} \mathrm{s}^{-1}$ ) change in the growing season by a vegetation feedback effect $(\mathrm{FV}-\mathrm{V}), \mathbf{b} \mathrm{CO}_{2}$ radiative effect $(\mathrm{F}-\mathrm{P})$, and $\mathbf{c}$ all effects $(\mathrm{FV}-\mathrm{P})$. The contour interval of zonal wind is $0.01 \mathrm{~m} \mathrm{~s}^{-1}$

heat flux by synoptic eddies, which leads to atmospheric cooling in the upper troposphere.

The atmospheric circulation changes caused by vegetation feedback (Fig. 6a) are clearly discernable even when compared with that induced by the $\mathrm{CO}_{2}$ radiative effect (Fig. 6b), although the temperature change from vegetation feedback (Fig. 6a) is much smaller than that from the $\mathrm{CO}_{2}$ effect (Fig. 6b). Perhaps this is because the changes in vegetation and associated surface temperature exhibit a zonally-elongated structure mostly concentrated around 50-70N, where the strong meridional temperature gradient with the strongest upper-level westerlies are found in summer. Hence such well-defined, large-scale anomalous temperature anomalies could efficiently induce large-scale circulation anomalies. Contrasting to the negative AO-like change from the vegetation feedback, the zonal wind changes from the $\mathrm{CO}_{2}$ effect resemble the pattern of the positive AO phase; the zonal wind is strengthened over $50-70 \mathrm{~N}$ while is slightly weakened in the mid-latitudes over 30-50N, indicating northward shift of the mid-latitude jet. Thus the circulation changes caused by vegetation feedback effect tend to counteract those caused by the $\mathrm{CO}_{2}$ radiative effect. Interestingly, the anticyclonic circulation anomalies in the Arctic from the vegetation feedback effect also contrast with the cyclonic circulation anomalies over the Arctic found in climate model experiments forced by reduced sea ice in summer and autumn (Alexander et al. 2004; Deser et al. 2010).

This atmospheric circulation change is not just a response associated with the surface changes, but seemingly plays an additional role in reinforcing the vegetation feedback effect (Figs. 3, 4). The anticyclonic circulation anomalies in the Arctic and high-latitude regions may lead to less cloudiness and more absorption of shortwave radiation at surface, which promote surface warming. The surface cooling in the mid-latitudes caused by the vegetation feedback can be partly explained by the cyclonic circulation anomalies. The anticyclonic anomaly and reduced zonal wind may allow more cold air from the Arctic to move southward, resulting in a cooling effect in the mid-latitudes, as suggested by Overland and Wang (2010). An increased cloudiness from the cyclonic circulation anomalies in the mid-latitudes may also provide a cooling effect.

\section{Summary and discussion}

In the present study, the possible amplification of highlatitude and Arctic warming in the growing season by vegetation feedbacks is investigated. Coupled vegetationclimate model simulations suggest that, in the growing season, circumpolar greening in the high-latitudes amplifies surface warming, primarily by inducing more absorption of incoming SW radiation. In addition, our modeling results show that large-scale circulation changes arising from the vegetation feedback effects further strengthen the Arctic warming by forming high-pressure anomalies over the Arctic sea. In accordance with previous studies, the present results again emphasize the importance of incorporating vegetation feedback effects into climate change projections. Because the climate change projections of the IPCC AR4 were modelled with fixed (present day) vegetation, our results indicate that the IPCC projections may have underestimated the warming over the polar region, but overestimated the warming over the mid-latitudes. 
(a) zonal mean Q \& $\mathrm{T}$ change: FV-F
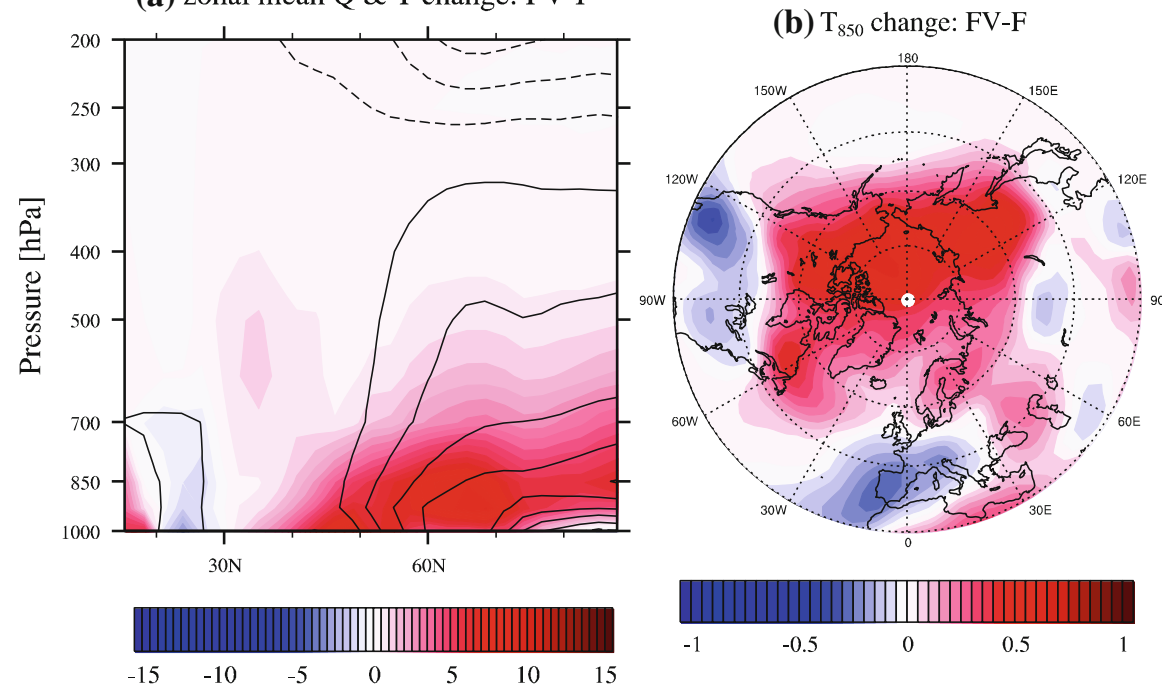

(c) $\mathrm{Q}_{850}$ change: FV-F
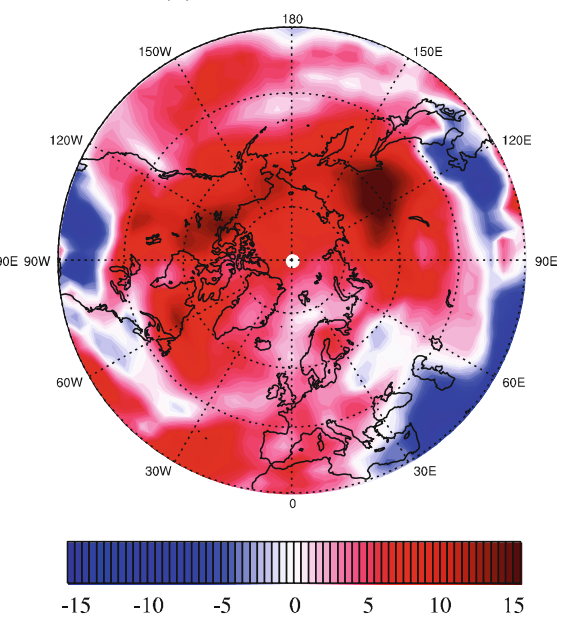

Fig. 7 a Zonal mean specific humidity (shading, unit: $x 1 . e^{-5} \mathrm{~g} / \mathrm{kg}$ ) and temperature (contours, unit: ${ }^{\circ} \mathrm{C}$ ) change by vegetation feedback effect (FV-F). The contour interval of temperature is $0.1^{\circ} \mathrm{C}$. Changes

In winter, the diminishing Arctic sea ice is the main driver of the amplified surface warming in the Arctic region under increasing concentrations of greenhouse gases (Screen and Simmonds 2010), and the arctic amplification is further contributed by the enhanced greenhouse effect associated with increases in water vapor (Schneider et al. 1999). Despite being less prominent in the growing season, the feedback associated with water vapor increases also contributes to the amplified warming in growing season through the vegetation feedback. In addition to the increased moisture-holding capability due to the warmer temperature, enhanced surface evapotransipiration by enhanced vegetation activity may induce an increase in tropospheric moisture content over the high-latitude and Arctic region (Fig. 7). It is very likely that the additional greenhouse effect caused by water-vapor feedback reinforces the Arctic warming in the lower to mid troposphere. Indeed, modeling by Swann et al. (2010) suggested that the Arctic warming induced by increased water-vapor from enhanced transpiration is up to 1.5 times larger than the warming induced by albedo changes from conversion of the bare ground to deciduous forests.

There are some important caveats when interpreting the results of this study. The suggested Arctic warming and circulation change caused by the vegetation feedback may lead to additional changes in sea ice and ocean circulation, but this is not taken into consideration in our present modeling system. Certainly, such changes could affect the ocean circulation and sea ice cover and thickness, which would invoke considerable feedback effects. For instance, the anticyclonic atmospheric circulation response from the vegetation feedback effect (Fig. 5) may cause sea ice in $\mathbf{b}$ temperature and $\mathbf{c}$ specific humidity at $850 \mathrm{hPa}$ in the growing season by vegetation feedback effect

change. The Ekman drift associated with the anticyclonic circulation in the Arctic tend to move ice away from the coast, which consequently will reduce the overall ice area (Ogi and Wallace 2007). Such sea ice changes may then affect the climate in the following autumn and winter, as well as summer. Besides, the Arctic warming and humidity increases caused by the vegetation feedback effect are not confined to sub-Arctic landmasses, but span most parts of the Arctic Ocean (see Fig. 7b, c). Presumably this also enhances the Arctic warming by melting more sea ice. Swann et al. (2010) shows this feedback effect can be arisen by the vegetation feedback in the high-latitudes. We plan to address these issues with a series of experiments by using a GCM with fully sea ice and ocean model.

Also the limitations of the DGVM need to be carefully noted. First, the simulated potential vegetation has discrepancies against observed vegetation. CAM3-DGVM tends to underestimate the forest cover, but overestimate the grass cover (Bonan and Levis 2006). This is also the case in the simulated vegetation in northern high-latitudes. Another important discrepancy is the missing treatment of some important plant species in the Arctic ecosystem such as shrubs, sedges, and mosses. Especially, an increase in abundance and extent of shrubs in tundra area is one expected response to climate warming (Walker and Coauthors 2006). Compared to other arctic plants in the tundra, shrubs have a lower albedo and a stronger interaction with snow, and therefore a stronger positive feedback effect on the climate warming is expected (Sturm et al. 2001; Chapin et al. 2005). Grass and some other tree species undertake the shrub's role in the present CCSM3DGVM and the simulated vegetation changes. However, in 
a broad sense, the simulated change in vegetation under an elevated $\mathrm{CO}_{2}$ concentration reflects the 'more greening in the high-latitudes under surface warming' that has been widely suggested by previous observation and modeling studies (e.g. Levis et al. 1999; Notaro et al. 2007; Swann et al. 2010). Therefore, the suggested feedback effects provide possible consequences from the enhanced vegetation in the high-latitudes, despite the discrepancies and limitations mentioned above. The second limitation with the usage of DGVM is that the vegetation feedback effect based on 'potential' vegetation change can be unrealistic in regions where there are large anthropogenic influences on land-use. Anthropogenic land-use changes, such as cultivation, irrigation, urbanization, and deforestation, have greatly influenced local climate, but this was not taken into account in the present modeling system. Necessarily, such considerations may have crucial influences on regionalscale climate changes, as well as on hydrological and biogeochemical changes. However, Myhre et al. (2005) estimated the radiative forcing caused by anthropogenic vegetation changes between pre-agricultural times to present to be modest in global average $\left(-0.09 \mathrm{Wm}^{-2}\right)$, and minimal in the high-latitudes where this study is focussed. Also to note is that changes in the carbon cycle by vegetation, and their possible feedback effects on climate change, are not considered in the present study. The atmospheric concentration of $\mathrm{CO}_{2}$ is considerably modulated by vegetation's uptake and storage of carbon, and the overlying climate determines the efficiencies of those processes. In particular, the present study suggests a large vegetation increase and amplified warming by the vegetation feedback effect over the permafrost regions where massive amount of organic carbon are stored in soils (Schuur et al. 2008). Because thawing permafrost, from warming and the resulting microbial decomposition of frozen organic carbon, is expected to give a significant feedback effect by releasing carbon to the atmosphere (Davidson and Janssens 2006; Zimov et al. 2006; Schuur et al. 2008), the competition between carbon uptake from above-ground greening and microbial decomposition of below-ground organic carbon needs to be carefully examined in order to accurately predict the climate feedbacks from terrestrial ecosystems under a changing climate.

Acknowledgments JH Jeong acknowledges support from the centre of Earth System Science at University of Gothenburg (TELLUS) and APEC Climate Center (APCC) international research project. BM Kim was supported by Korea Meteorological Administration Research and Development Program under Grant RACS_2011-2019 (PN11020). JS KUG was supported by KORDI (PE98651). This work was partly supported by the National Research Foundation of Korea (NRF) grant funded by the Korea government (MEST) (No. 20090093458). The authors are thankful for technical support for CAM3-DGVM experiments by Dr. Su-Jong Jeong, and the insightful comments from three anonymous reviewers.

\section{References}

Alexander MA, Bhatt US, Walsh JE, Timlin MS, Miller JS, Scott JD (2004) The atmospheric response to realistic Arctic sea ice anomalies in an AGCM during winter. J Climate 17(5):890-905

ACIA (2005) Arctic Climate Impact Assessment. Cambridge University Press, Cambridge

Bonan GB (2008) Ecological climatology: concepts and applications. Cambridge University Press, Cambridge

Bonan GB, Levis S (2006) Evaluating aspects of the community land and atmosphere models (CLM3 and CAM3) using a dynamic global vegetation model. J Climate 19(11):2290-2301

Bonan GB, Pollard D, Thompson SL (1992) Effects of boreal forest vegetation on global climate. Nature 359(6397):716-718

Bunn AG, Goetz SJ, Kimball JS, Zhang K (2007) Northern highlatitude ecosystems respond to climate change. EOS 88(34):333-340

Chapin FS (1983) Direct and indirect effects of temperature on arctic plants. Polar Biol 2(1):47-52

Chapin FS (1987) Environmental controls over growth of tundra plants. Ecol Bull 38:69-76

Chapin FS, Sturm M, Serreze MC, McFadden JP, Key JR, Lloyd AH, McGuire AD, Rupp TS, Lynch AH, Schimel JP, Beringer J, Chapman WL, Epstein HE, Euskirchen ES, Hinzman LD, Jia G, Ping CL, Tape KD, Thompson CDC, Walker DA, Welker JM (2005) Role of land-surface changes in Arctic summer warming. Science 310(5748):657-660

Chapman WL, Walsh JE (2007) Simulations of Arctic temperature and pressure by global coupled models. J Climate 20(4):609-632

Collins WD, Rasch PJ, Boville BA, Hack JJ, Williamson DL, Kiehl JT, Briegleb B, Bitz C, Lin S-J, Zhang M, Dai Y (2004) Description of the NCAR community atmosphere model (CAM 3.0). National Center for Atmospheric Research, Boulder, Colorado

Collins WD, Bitz CM, Blackmon ML, Bonan GB, Bretherton CS, Carton JA, Chang P, Doney SC, Hack JJ, Henderson TB, Kiehl JT, Large WG, McKenna DS, Santer BD, Smith RD (2006) The Community Climate System Model version 3 (CCSM3). J Climate 19(11):2122-2143

Davidson EA, Janssens IA (2006) Temperature sensitivity of soil carbon decomposition and feedbacks to climate change. Nature 440:165-173

Deser C, Tomas R, Alexander M, Lawrence D (2010) The seasonal atmospheric response to projected arctic sea ice loss in the late twenty-first century. J Climate 23(2):333-351

Foley JA (2005) Tipping points in the tundra. Science 310(5748):627-628

Foley JA, Kutzbach JE, Coe MT, Levis S (1994) Feedbacks between climate and boreal forests during the Holocene Epoch. Nature 371(6492):52-54

Jeong SJ, Ho CH, Jeong JH (2009) Increase in vegetation greenness and decrease in springtime warming over east Asia. Geophys Res Lett 36:L02710

Kug J-S, Choi D-H, Jin F-F, Kwon W-T, Ren H-L (2010a) Role of synoptic eddy feedback on polar climate responses to the anthropogenic forcing. Geophys Res Lett 37(14):L14704

Kug J-S, Jin F-F, Park J, Ren H-L, Kang I-S (2010b) A general rule for synoptic-eddy feedback onto low-frequency flow. Clim Dyn 35(6):1011-1026

Levis S, Foley JA, Pollard D (1999) Potential high-latitude vegetation feedbacks on CO2-induced climate change. Geophys Res Lett 26(6):747-750

Levis S, Bonan GB, Vertenstein M, Oleson KW (2004) The community land model's dynamic global vegetation model (CLM-DGVM). National Center for Atmospheric Research, Boulder, Colorado 
Min SK, Zhang XB, Zwiers F (2008) Human-induced arctic moistening. Science 320(5875):518-520

Mooney HA, Canadell J, Chapin FS, Ehleringer JR, Körner C, McMurtrie RE, Parton WJ, Pitelka LF, Shulze E-D (1999) Ecosystem physiology responses to global change. In: Walker $\mathrm{BH}$, Steffen W, Canadell JG, Ingram J (eds) Terrestrial biosphere and global change: implications for natural and managed ecosystems. Cambridge University Press, Cambridge, pp 141-149

Myhre G, Kvalevåg MM, Schaaf CB (2005) Radiative forcing due to anthropogenic vegetation change based on MODIS surface albedo data. Geophys Res Lett 32(21):L21410

Notaro M, Liu ZY (2008) Statistical and dynamical assessment of vegetation feedbacks on climate over the boreal forest. Clim Dyn 31(6):691-712

Notaro M, Vavrus S, Liu ZY (2007) Global vegetation and climate change due to future increases in $\mathrm{CO} 2$ as projected by a fully coupled model with dynamic vegetation. J Climate 20(1):70-90

Ogi M, Wallace JM (2007) Summer minimum Arctic sea ice extent and the associated summer atmospheric circulation. Geophys Res Lett 34(12):L12705

O'ishi R, Abe-Ouchi A (2009) Influence of dynamic vegetation on climate change arising from increasing $\mathrm{CO} 2$. Clim Dyn 33(5):645-663

Oleson KW, Dai Y, Bonan G, Bosilovich M, Dirmeyer PA, Hoffman F, Houser P, Levis S, Niu GY, Thornton P, Vertenstein M, Yang Z-L, Zeng XB (2004) Technical description of the community land model (CLM). National Center for Atmospheric Research, Boulder, Colorado

Overland JE, Wang M (2010) Large-scale atmospheric circulation changes are associated with the recent loss of Arctic sea ice. Tellus A 62(1):1-9

Rayner NA, Parker DE, Horton EB, Folland CK, Alexander LV, Rowell DP, Kent EC, Kaplan A (2003) Global analyses of sea surface temperature, sea ice, and night marine air temperature since the late nineteenth century. J Geophys Res-Atmos 108(D14):4407

Rothrock DA, Yu Y, Maykut GA (1999) Thinning of the Arctic seaice cover. Geophys Res Lett 26(23):3469-3472

Schneider EK, Kirtman BP, Lindzen RS (1999) Tropospheric water vapor and climate sensitivity. J Atmos Sci 56(11):1649-1658

Schuur EAG, Bockheim J, Canadell JG, Euskirchen E, Field CB, Goryachkin SV, Hagemann S, Kuhry P, Lafleur PM, Lee H, Mazhitova G, Nelson FE, Rinke A, Romanovsky VE, Shiklomanov N, Tarnocai C, Venevsky S, Vogel JG, Zimov SA (2008) Vulnerability of permafrost carbon to climate change: implications for the global carbon cycle. Bioscience 58(8):701-714

Screen JA, Simmonds I (2010) The central role of diminishing sea ice in recent Arctic temperature amplification. Nature 464(7293): $1334-1337$
Serreze MC, Walsh JE, Chapin FS, Osterkamp T, Dyurgerov M, Romanovsky V, Oechel WC, Morison J, Zhang T, Barry RG (2000) Observational evidence of recent change in the northern high-latitude environment. Clim Change 46(1-2):159-207

Sitch S, Smith B, Prentice IC, Arneth A, Bondeau A, Cramer W, Kaplan JO, Levis S, Lucht W, Sykes MT, Thonicke K, Venevsky S (2003) Evaluation of ecosystem dynamics, plant geography and terrestrial carbon cycling in the LPJ dynamic global vegetation model. Glob Change Biol 9(2):161-185

Solomon S, Intergovernmental Panel on Climate Change, Intergovernmental Panel on Climate Change. Working Group I. (2007) Climate change 2007 the physical science basis: contribution of Working Group I to the Fourth Assessment Report of the Intergovernmental Panel on Climate Change. Cambridge University Press, Cambridge

Sturm M, Racine C, Tape K (2001) Climate change-Increasing shrub abundance in the Arctic. Nature 411(6837):546-547

Swann AL, Fung IY, Levis S, Bonan GB, Doney SC (2010) Changes in Arctic vegetation amplify high-latitude warming through the greenhouse effect. PNAS 107(4):1295-1300

Tape K, Sturm M, Racine C (2006) The evidence for shrub expansion in Northern Alaska and the Pan-Arctic. Glob Change Biol 12(4):686-702

Thompson DWJ, Wallace JM (1998) The Arctic Oscillation signature in the wintertime geopotential height and temperature fields. Geophys Res Lett 25(9):1297-1300

Tjernström M, Graversen RG (2009) The vertical structure of the lower Arctic troposphere analysed from observations and the ERA-40 reanalysis. Q J Roy Meteor Soc 135(639):431-443

Tucker CJ, Slayback DA, Pinzon JE, Los SO, Myneni RB, Taylor MG (2001) Higher northern latitude normalized difference vegetation index, growing season trends from 1982 to 1999 . Int J Biometeorol 45(4):184-190

Walker MD et al (2006) Plant community responses to experimental warming across the tundra biome. Proc Natl Acad Sci 103(5):1342-1346

Watson RT (2000) Land use, land-use change, and forestry: a special report of the IPCC. Cambridge University Press, Cambridge

Zhang J, Walsh JE (2006) Thermodynamic and hydrological impacts of increasing greenness in Northern high latitudes. J Hydrometeorol 7(5):1147-1163

Zhou L, Tucker CJ, Kaufmann RK, Slayback D, Shabanov NV, Myneni RB (2001) Variations in northern vegetation activity inferred from satellite data of vegetation index during 1981 to 1999. J Geophys Res 106(D17):20069-20083

Zimov SA, Schuur EAG, Chapin FS (2006) Permafrost and the global carbon budget. Science 312:1612-1613 